\title{
Pemberdayaan Perempuan Melalui UMKM Pada Ibu-Ibu Majelis Taklim Namirah
}

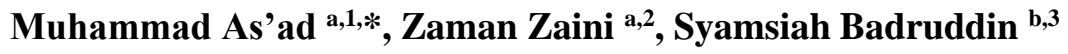

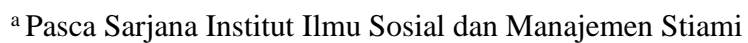 \\ ${ }^{\mathrm{b}}$ Fakultas Ilmu Sosial dan Ilmu Politik Universitas Nasional \\ ${ }^{1}$ muhmmad.asad@stiami.ac.id *; ${ }^{2}$ zamanzaini@yahoo.co.id; ${ }^{3}$ chiah_jurnal2006@yahoo.com \\ * corresponding author
}

\section{ARTICLE INFO}

\section{Article history}

Received

Revised

Accepted

\section{Keywords}

Women's Empowerment,

UMKM,

Majelis Taklim Namirah

\begin{abstract}
The economic burden that is so heavy is felt by most housewives as financial managers. Therefore, mothers must be able to manage their finances properly and also empower themselves by increasing income through Micro, Small and Medium Enterprises.

Applying the right way of financial management, the housewife is expected to get the maximum benefits from the money she has at this time so that it can ultimately be beneficial for improving the welfare of life while increasing family income through MSMEs.

Majelis Taklim/MT Namirah is a member of the Majelis Taklim who live in Makassar City, South Sulawesi as the partner of this activity.

Alternative problem solving is done by conducting public lectures for MT Ibu-ibu Namirah by the post graduate lecturer at the Institut Ilmu Sosial dan Manajemen Stiami, according to their competence, namely Family Development in household, Women's Participation in politics, and Management of Household Finances and Women's Empowerment in MSMEs. Some factors that support the implementation of community service activities by conducting public lectures are the amount of interest and enthusiasm of the mothers as participants in the activities so that the activities take place smoothly and in an orderly manner. While the limiting factor is the limited time for public lectures.

This activity can increase the knowledge and understanding of MT Namirah ladies about financial management and types of businesses, knowing tips for dealing with obstacles in managing household finances and MT women's businesses. Namirah, and get the knowledge and understanding of MT Namirah about the need for halal financial sources in financial management.
\end{abstract}

\section{A. PENDAHULUAN}

\section{Analisis Situasi}

Beban ekonomi yang begitu berat dirasakan oleh hampir sebagian besar ibu-ibu rumah tangga sebagai pengelola keuangan .Karena itu ibu harus mampu mengelola keuangannya secara baik dan benar dan juga memberdayakan diri dengan menambah penghasilan melalui usaha Mikro, Kecil dan Menengah.

Penerapan cara pengelolaan keuangan yang benar, maka ibu rumah tangga diharapkan bisa mendapatkan manfaat yang maksimal dari uang yang dimilikinya pada saat ini sehingga pada akhirnya dapat bermanfaat bagi peningkatan kesejahteraan hidup sekaligus menambah pendapatan keluarga melalui UMKM.

Namun mengelola keuangan pribadi dan usaha bukanlah hal yang mudah untuk dilakukan sebab ada saja kesulitan yang dihadapi oleh setiap orang,dimana salah satu kesulitan yang dihadapi adalah mencampur adukkan hasil usaha dan pribadi serta budaya konsumtif dan meninggalkan anjuran syariah islam .

Oleh karena itu mengelola keuangan usaha perlu kita teladani sebagai mana yang dilakukan oleh sahabat nabi yang bernama Salman Alfarizi ,dimana suatu ketika beliau membuat anyaman dengan modal satu dirham (perak) dan menjualnya seharga tiga dirham (Perak) lalu hasil tiga dirham tersebut dibagi 1/3 bagian yaitu satu dirham untuk kebutuhan sehari-hari dan satu dirham untuk shadaqah serta satu dirham lagi untuk modal kembali.Kaitan mengeluarkan shadaqah dengan usaha memberikan keuntungan yang sangat 
besar bagi pelaku usaha .Salah satu keuntungannya adalah berlpatnya rizqi. Hal ini sesuai firman Allah SWT dalam Surat Al-Baqarah ayat 261 dan hal tersebutlah yang belum disadari oleh sebagian pelaku usaha UMKM.

Usaha Mikro Kecil dan Menengah (UMKM) adalah usaha produktif yang dimiliki perorangan maupun badan usaha yang telah memenuhi kriteria sebagai usaha mikro.Pendapat lain mendifinisikan adalah unit usaha produktif yang berdiri sendiri disemua sektor ekonomi (Tulus Tambunan,2012). Seperti halnya Keputusan Presiden RI nomor 99 tahun 1998 pengertian Usaha Kecil adalah: "Kegiatan ekonomi rakyat yang berskala kecil dengan bidang usaha yang secara mayoritas merupakan kegiatan usaha kecil. Dan perlu di lindungi untuk mencegah dari persaingan usaha yang tidak sehat."

Definisi usaha mikro di artikan sebagai usaha ekonomi produktif yang di miliki perorangan maupun badan usaha sesuai dengan kriteria usaha mikro. Usaha yang termasuk kriteria usaha mikro adalah usaha yang memiliki kekayaan bersih mencapai $\mathrm{Rp} 50.000 .000$,- dan tidak termasuk bangunan dan tanah tempat usaha. Mempunyai hasil penjualan usaha mikro setiap tahunnnya paling banyak Rp 300.000.000,-

Berdasarkan definisi dan konsep di atas maka pemberdayaan merupakan salah satu upaya untuk mendorong dan meningkatkan potensi sumber daya masyarakat. (Vikaliana et al., 2017). Pada kegiatan ini yang menjadi mitra adalah Ibu-ibu yang tergabung pada Majelis Taklim/ MT Namirah dalam rangka menambah penghasilan keluarga melalui UMKM. Ibu-Ibu MT Namirah ini merupakan Ibu-ibu anggota majelis taklim yang berdomisili di Kota Makassar, Sulawesi Selatan.

\section{Perumasan masalah}

1. Bagaimanakah pengelolaan keuangan rumah tangga Ibu-ibu MT.Namirah dan jenis usaha yang dilakukan sebagai tambahan penghasilan?

2. Kendala apa yang dihadapi dalam pengelolaan keuangan rumah tangga dan usaha Ibu-ibu MT. Namirah?

3. Apa kaitan Pengeluaran sadaqah atas usaha yang dilakukan oleh Ibu-ibu MT. Namirah ?

\section{Tujuan Kegiatan}

1. Menjelaskan cara pengelolaan keuangan rumah tangga bagi ibu-ibu MT.Namirah dan jenis usaha yang dilakukan sebagai tambahan penghasilan?

2. Menjelaskan Kendala apa yang dihadapi dalam pengelolaan keuangan rumah tangga dan usaha ibu-ibu MT. Namirah ?

3. Menjelaskan kaitan pengeluaran sadaqah atas usaha yang dilakukan oleh ibu-ibu MT. Namirah ?

\section{Manfaat Kegiatan}

Setelah memahami dan menguasai konsep Rumah tangga dan Pengelolaan Keuangan ibu-ibu MT. Namirah mampu memahami cara-cara pengelolaan keuangan rumah tangga dan jenis usaha yang bisa dilakukan serta manfaat sumber-sumber keuangan yang halal sesuai dengan ajaran Al-Qur'an dan Hadist.agar memperoleh keberkahan dalam pengelolaannya.

\section{B. PELAKSANAAN DAN METODE}

\section{Pelaksanaan}

Alternatif pemecahan masalah dilakukan dengan melakukan kuliah umum bagi ibu-ibu MT. Namirah oleh dosen pasca sarjana sesuai kompetensinya antara lain dengan Tema :

1. Prof Syamsiah Badruddin ( Pembinanaa Keluarga dalam rumah Tangga )

2. Dr. Zaman Zaieni ( Partisipasi Perempuan dalam politik)

3. Dr. Muhammad As'ad (Pengelolaan Keuangan Rumah Tangga Dan Pemberdayaan Perempuan dalam UMKM )

Sebelum kegiatan dilaksanakan maka dilakukan persiapan-persiapan sebagai berikut:

1. Melakukan studi pustaka tentang UMKM ,Rumah Tangga dan Pengelolaan Keuangan.

2. Melakukan persiapan materi kuliah umum tentang UMKM ,Rumah Tangga dan Pengelolaan Keuangan.

3. Menentukan waktu dan tempat pelaksanaan kegiatan pengabdian bersama-sama tim pelaksana

Pelaksanaan kegiatan pengabdian berlangsung pada 11-13 Maret 2018 jam 09.00-12.00 yang dihadiri oleh 100 peserta (Ibu-ibu MT. Namirah) di Hotel Asia, Makassar, Sulawesi Selatan. Kegiatan pengabdian 
ini memiliki relevansi dengan perubahan sikap individu dalam tata cara mengelola keuangan peribadi dan usaha sesuai dengan Alqur'an dan Al-Hadist para Ibu-ibu MT Namirah.

\section{HASIL DAN PEMBAHASAN}

\section{Hasil}

Berdasarkan wawancar dan tanya jawab kegiatan pengabdian ini memberikan hasil sebagai berikut:

a. Meningkatkan pengetahuan tentang Pengelolaan Keuangan dan jenis-jenis usaha sebagai tambahan penghasilan.

b. Memberikan pemahaman tentang pentingnya Pengelolaan Keuangan.

c. Menanamkan kesadaran perlunya sumber keuangan yang halal dalam pengelolaan keuangan Ibu-ibu MT. Namirah

Gambar 1 berikut menunjukkan bagaimana kegiatan ini dilakukan

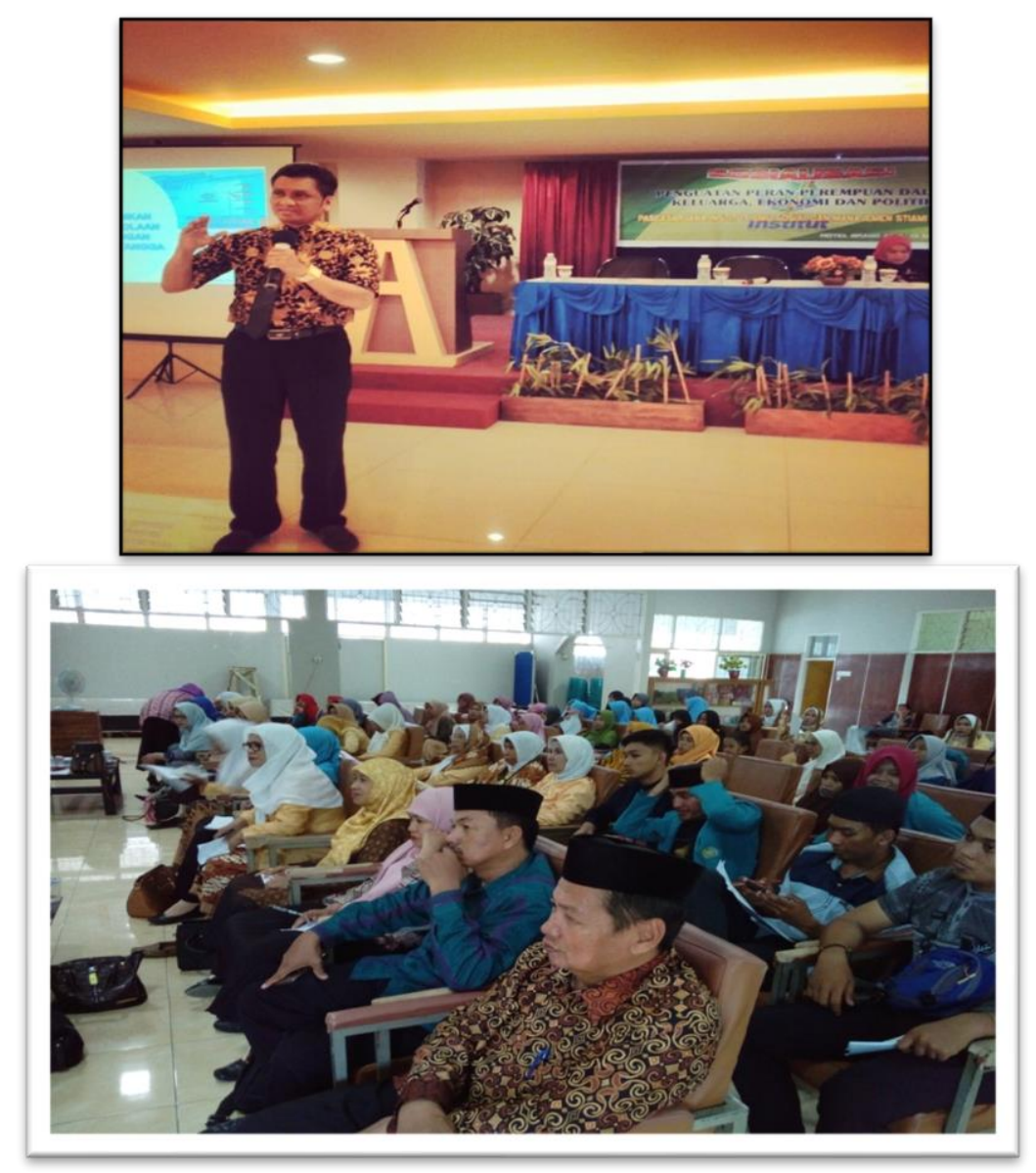

Gambar 2 Kegiatan Kuliah Umum pada Ibu-Ibu Majelis Taklim Namirah, Makassar, Sulawesi Selatan

\section{E. PEMBAHASAN}

Beberapa faktor yang mendukung terlaksananya kegiatan pengabdian dengan melakukan kuliah umum adalah besarnya minat dan antusiasme para ibu-ibu sebagai peserta kegiatan sehingga kegiatan berlangsung dengan lancar dan tertib. Sedangkan faktor penghambatnya adalah keterbatasan waktu kuliah umum.

\section{F. PENUTUP}

\section{Simpulan}

Dari kegiatan pengabdian pada masyarakat ini dapat disimpulkan bahwa kegiatan ini dapat meningkatkan pengetahuan dan pemahaman Ibu-ibu MT. Namirah tentang pengelolaan keuangan dan Jenis usaha, mengetahui kiat-kiat menghadapi kendala dalam pengelolaan keuangan rumah tangga dan usaha Ibu- 
ibu MT. Namirah, dan mendapatkan pengetahuan dan pemahaman Ibu-ibu MT. Namirah tentang perlunya sumber-sumber keuangan yang halal dalam pengelolaan keuangan

\section{Saran}

Mengingat besarnya manfaat kegiatan pengabdian berupa kuliah umum Pengelolan Keuangan rumah Tangga MT. Namirah maka selanjutnya perlu mengadakan kuliah umum mengenai pengelolaan keuangan di setiap organisasi. Selain itu adanya kesinambungan dan monitoring program pasca kegiatan pengabdian kuliah umum sehingga para Ibu-ibu mengaplikasikannya dalam setiap kegiatannya.

\section{G. DAFTAR PUSTAKA}

[1]. Al-Qur'an dan terjemahannya, Departemen Agama Republik indonesia, pustaka Agung harapan,2006

[2]. Badan Pusat statistik Jakarta pusat, Pedoman pendataan Survei sosial Ekonomi nasional,2013

[3]. Edward Dedy Ciri-Ciri Usaha UMKM,Pengertian dan Ciri-Ciri UMKM,2008

[4]. Jr Wachowicz \&Horn, Fundamental of Financial management, 8th edition,2012

[5]. Kepututsan Presiden RI No.99 tahun 1998

[6]. Kartasasmita ginanjar,Pembangunan untuk rakyat,Pustaka Cisindo,1996

[7]. Meredith, G, G, et all, "Kewirausahaan (Teori dan Praktek)", Seri Manajemen No. 97, Alihbahasa: Andre Asparsayogi, edisi ke V, PT Pustaka Binaman Pressindo, Jakarta,1996

[8]. Mantra bagoes Ida, Demografi Umum,pustaka belajar,2003

[9]. Setiawan, Ensklopedi Nasional Indonesia,PT. Delta pamungkas, 2004

[10].Sartono Agus ,Manajemen Keuangan,Edisi III BPFB ,2001

[11].Stoner, J, A, F., Freeman R, E., and Gilbert Jr, D, R., "Manajemen", Alih bahasa: Alexander Sindoro, Jilid I, PT Prenhalindo, Jakarta,1996

[12].Suhendra,Peranan birokrasi dalam Pemberdayaan Masyarakat,alfabeta,Bandung, 2006

[13].Tambunan Tulus (Usaha Mikro kecil dan menengah di Indonesia (UMKM) : Isu-Isu penting,Jakarta,LP3ES,2012

[14].Undang-Undang No.20 Tahun 2008 tentang Usaha mikro, kecil dan menengah (UMKM)

[15].Widjaja A W,Administrasi Kepegawaian,suatu pengantar,TB Rahmah,Solo,2003

[16].Vikaliana, R., Harsanti, D., Wulandari, D. S., \& Andayani, A. (2017). A Cluster Model for Increasing Performance of Small and Medium-Scale Enterprises (A Case Study in Bogor, Indonesia). https://doi.org/https://doi.org/10.1007/978-981-287-661-4_15 